\title{
ANÁLISE DE QUANTITATIVOS PROVENIENTES DE UM MODELO BIM PARA ADEQUAÇÃO AO PŔOCESSO ORÇAMENTÁRIO DAS EMPRESAS DE CONSTTRUÇÃO CIVIL
}

\author{
Analysis of quantities from a BIM model to attend a cost estimation process \\ of civil construction companies
}

Denise Latreille', Sergio Scheer ${ }^{1}$

RESUMO: Este artigo tem como objetivo analisar quantitativos provenientes de um modelo BIM para utilização em processos orçamentários previamente estabelecidos em empresas de construção civil. A pesquisa bibliográfica aponta que a dificuldade da implantação de BIM em conjunto com a orçamentação é um problema causado pela falta de padronização e subjetividade inerentes ao processo de orçamentação. No estudo de caso apresentado, o mesmo projeto foi quantificado de duas maneiras distintas. Uma delas foi a quantificação denominada tradicional, que envolve a interpretação de projetos em duas dimensões e registro dos dados coletados em planilhas. A outra forma de quantificação se desenvolveu com base na Modelagem da Informação da Construção (Building Information Modeling - BIM). Como resultado do estudo de caso, foram obtidos dois conjuntos de quantitativos referentes às mesmas atividades. Análises sobre os resultados foram realizadas para verificar a possibilidade de validação de um modelo BIM por pessoas que não estejam envolvidas diretamente na modelagem (gerentes de custo e orçamentistas, por exemplo). Com um modelo validado, é possível utilizar os dados gerados pelo software BIM e ganhar tempo na orçamentação.

PALAVRAS-CHAVE: BIM; Quantitativos; Orçamento; Validação.

\begin{abstract}
This paper aims to analyze the quantity take-off from a BIM model for use in cost estimation processes previously established in construction companies. Bibliographic research points out that the difficulty of implementing BIM in conjunction with budgeting is a problem caused by the lack of standardization and subjectivity inherent in the process. In the case study presented, the same project was quantified in two different ways. One of them was called traditional quantification, which involves the interpretation of two-dimensional projects and the recording of data collected in spreadsheets. The other form of quantification was developed based on Building Information Modeling (BIM). As a result of the case study, two sets of quantitative data regarding the same activities were obtained. Result analyses were performed to verify if the validation of a BIM model by people not directly involved in the modeling (cost managers and budget planner, for example) is possible. With a validated model, data generated by BIM software can be used and save time on cost estimation.
\end{abstract}

KEYWORDS: BIM; Quantity take-off; Cost estimation; Validation.
How to cite this article:

LATREILLE, D.; SCHEER, S. Análise de quantitativos provenientes de um modelo BIM para adequação ao processo orçamentário das empresas de construção civil. Gestão e Tecnologia de Projetos, São Carlos, v.16, n.1, p.96-108, jan.2021. http://dx.doi.org/10.116/gtp.v16i1.163499
Fonte de financiamento:

Conflito de interesse:

Declara não haver

Submetido em: 24/10/2019

Aceito em: $16 / 12 / 2020$

[Disponivel online em Dezembro de 2020] 


\section{INTRODUÇÃO}

A implantação da Modelagem da Informação da Construção (Building Information Modeling - BIM) incorre em mudanças não apenas na fase de projeto, mas também durante o ciclo de vida de uma edificação. A forma de interação entre as pessoas envolvidas é uma das modificações provenientes do uso de BIM no setor da construção civil (SAKAMORI, 2015). Um benefício percebido pelas empresas que estão migrando para o uso de BIM em seus empreendimentos é que, devido à maior integração entre os envolvidos, há melhora na compatibilização do projeto, evitando problemas durante a fase de execução (MONTEIRO; MÊDA; MARTINS, 2014).

Visto que podem fornecer diversas informações, os modelos BIM podem ser classificados de acordo com suas finalidades. Por exemplo, um modelo BIM pode ser utilizado para fins de estimativa de custo, contendo informações a serem utilizadas no levantamento de quantitativos e precificação de atividades (SUCCAR; SALEEB; SHER, 2016).

A orçamentação de um projeto, quando feita sem a utilização de BIM, demanda tempo e organização, principalmente para a etapa de quantificação (SABOL, 2008). Visando a otimizar o processo orçamentário com relação à qualidade e à rastreabilidade da informação, assim como garantir a economia de tempo, as empresas de construção apostam cada vez mais na contratação de tecnologia BIM. No entanto, existe um problema que pode ocorrer durante a fase de implementação da tecnologia. Tendo como base a proposição de que a planilha orçamentária tende a estar consolidada nas empresas, o orçamentista deve, então, orientar o responsável pela modelagem BIM para que os quantitativos provenientes deste modelo representem uma informação que possa ser utilizada dentro de um processo de orçamento já firmado. Com base nisso, questiona-se como é possível que os quantitativos fornecidos pela modelagem sejam validados por terceiros.

O objetivo deste artigo é analisar os quantitativos provenientes de um modelo BIM, com foco na utilização desses dados para a substituição do processo tradicional de levantamento de quantitativos. A possibilidade de validar um modelo BIM para atender a uma planilha orçamentária já estabelecida pode contribuir para a melhoria do processo orçamentário, principalmente em empresas de construção que estão em fase de implementação da tecnologia BIM.

Este artigo foi produzido com base na dissertação de mestrado de Latreille (2018), cujo título é "Análise da validação de quantitativos obtidos de um modelo BIM de arquitetura para atender a estimativa orçamentária de empresas de construção civil”.

\section{REVISÃO DE LITERATURA}

Um modelo BIM deve ser elaborado de modo a permitir a extração de quantitativos de acordo com a estrutura da planilha orçamentária (LEE; KIM; YU, 2014). A intervenção humana é necessária para interpretar os dados advindos do modelo BIM, de forma a organizar a transformar um conjunto de dados em informações úteis ao orçamento (LIU; LU; AL-HUSSEIN, 2016). Monteiro e Martins (2013) afirmam que, como o orçamento é baseado na interpretação humana, está sujeito a erro.

A falta de padronização nos orçamentos e nos softwares de orçamentação fomentam a subjetividade desse processo (ABANDA; KAMSU-FOGUEM; TAH, 2017). Harrison e Thurnell (2015) alertam para o cuidado que deve ser tomado quanto à orientação dada para a modelagem. A comunicação pode desencorajar o trabalho conjunto entre modeladores e orçamentistas quando muitas regras de modelagem são impostas. A heterogeneidade da modelagem BIM e orçamentação levam à lenta adoção de BIM nessas atividades (LAWRENCE et al., 2014). Na pesquisa de Hartmann et al. (2012), 
a tentativa de implementar o BIM em uma organização gerou maior colaboração entre os envolvidos, que, por sua vez, permitiu customizar a implementação para atender às necessidades da empresa.

\section{BIM e validação}

Harrison e Thurnell (2015) sugerem que há inúmeros benefícios no BIM sobre os métodos tradicionais, principalmente através do aumento da eficiência e visualização que este modelo provê junto com a rápida identificação das mudanças de projeto. À medida que se aumenta o uso do BIM, ocorrerá uma mudança cultural na qual este modelo será visto como o caminho do futuro, e passará a ser amplamente utilizado pelos pesquisadores. Entretanto, devido a barreiras como projetos incompletos, falta de padrões para a orçamentação, questões legais e falta de suporte governamental, a realização destes benefícios encontra limitações.

A Figura 1, a seguir, descreve o processo de orçamentação através de um software BIM.
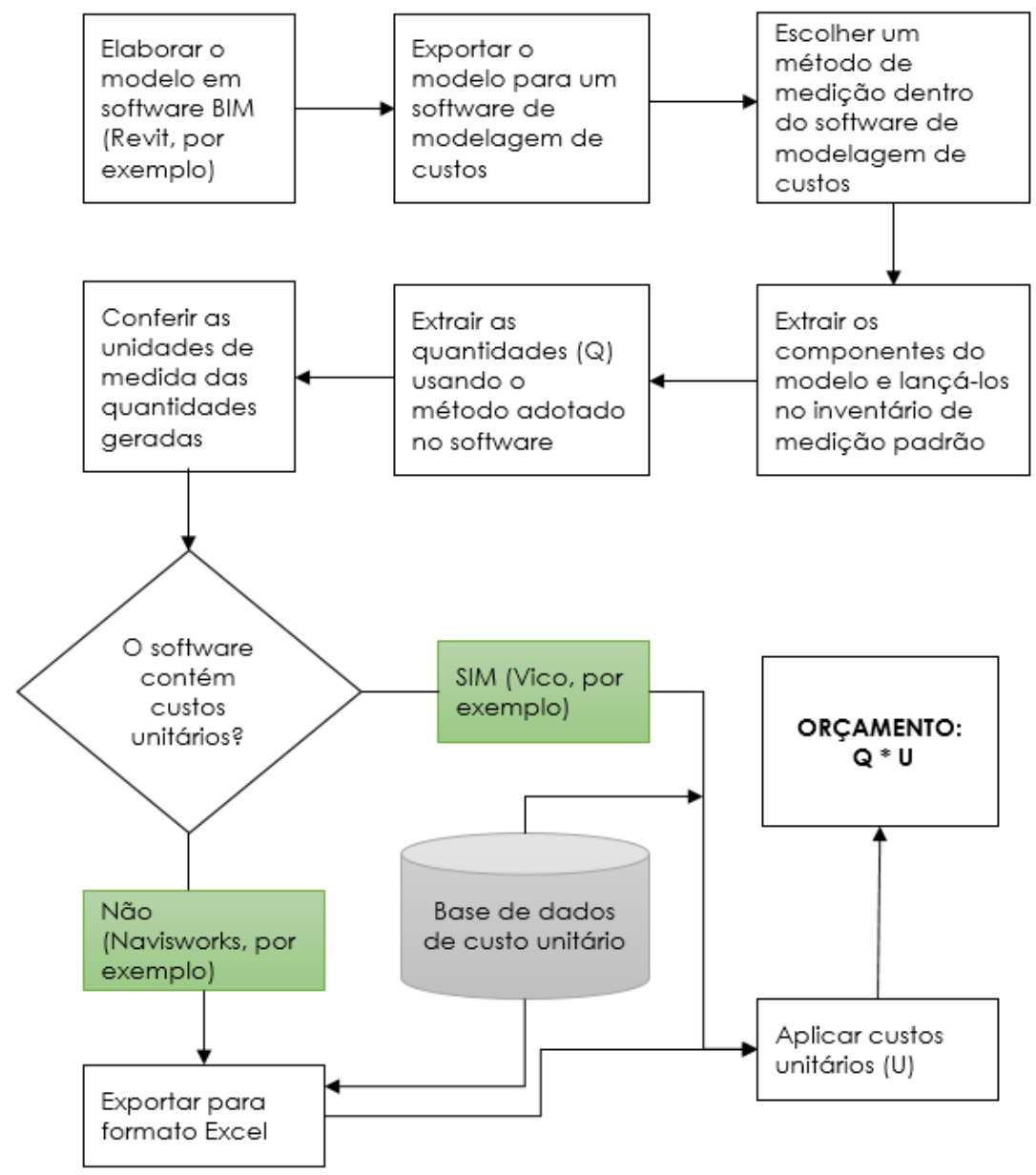

Figura 1: Processo de orçamentação em BIM

Fonte: Adaptado de Abanda, Kamsu-Foguem e Tah (2017, p. 444). 
O conteúdo de um modelo paramétrico deve ser validado para garantir resultados confiáveis. A validação dos modelos paramétricos deve ser um esforço conjunto feito pelos modeladores e pelo cliente para melhorar a qualidade das soluções do projeto e atender às necessidades do cliente. Portanto, verificar a modelagem na fase de quantificação é fundamental. Pode-se citar como exemplo um erro na modelagem de dois pisos sobrepostos, o que pode levar à dupla contagem dos materiais utilizados.

\section{MÉTODO DE PESQUISA}

Esta pesquisa é do tipo exploratória, cujo objetivo é o aprimoramento de ideias. A estratégia de pesquisa utilizada para a elaboração deste artigo é um estudo de caso, que, de acordo com Gil (2007), tem o propósito de explorar situações da vida real cujos limites não estão claramente definidos, descrever a situação do contexto em que está sendo feita a investigação, e explicar as variáveis causais de determinado fenômeno em situações complexas em que não é possível a utilização de estratégias como o levantamento e os experimentos.

A Figura 2 a seguir ilustra as três etapas da pesquisa. A primeira delas foi marcada pela compreensão da lacuna de conhecimento, com base na revisão de literatura, que buscou compreender em profundidade a temática e a validação de modelos BIM.

A segunda etapa foi a realização do estudo empírico, que utilizou o processo tradicional de orçamentação e o processo BIM para quantificar um mesmo projeto, resultando em dois conjuntos de quantitativos. Com base nesses resultados, foram realizadas duas análises. Uma delas avalia a comunicação entre os envolvidos durante o estudo empírico. Já a segunda compara o tempo consumido para a revisão do orçamento nos dois processos. Em seguida, na terceira etapa da pesquisa, realizou-se uma verificação dos quantitativos fornecidos pelo modelo BIM de arquitetura do projeto, visando à validação dos dados.

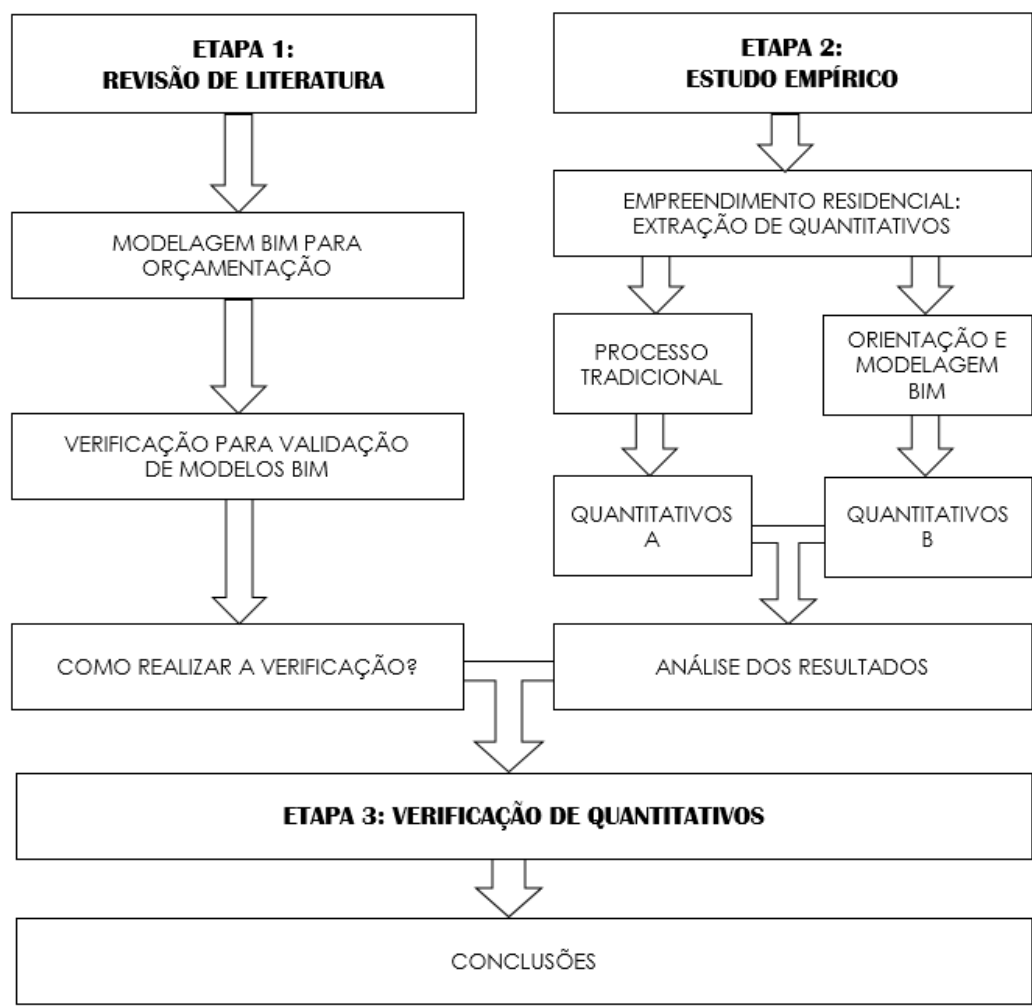

Figura 2: Etapas da pesquisa Fonte: Os autores. 


\section{Estudo empírico}

A orçamentação do projeto foi de responsabilidade da primeira autora deste artigo. Já a modelagem BIM do projeto foi realizada por uma empresa especializada no uso dessa tecnologia, neste estudo identificada como "empresa C". A empresa C recebeu orientação quanto à forma com que os dados poderiam ser modelados para que os quantitativos se adequassem à planilha orçamentária.

O estudo foi desenvolvido com base em um empreendimento localizado na cidade de Curitiba - PR. O empreendimento, com área construída de $7.231,86 \mathrm{~m}^{2}$, é composto por uma torre residencial (2 blocos), contendo dois subsolos, pavimento térreo e mais seis pavimentos acima do térreo, totalizando 35 apartamentos e 75 vagas de garagem. A vista 3D do empreendimento pode ser observada na Figura 3 abaixo.

Figura 3: Vista 3D do modelo Fonte: Os autores.

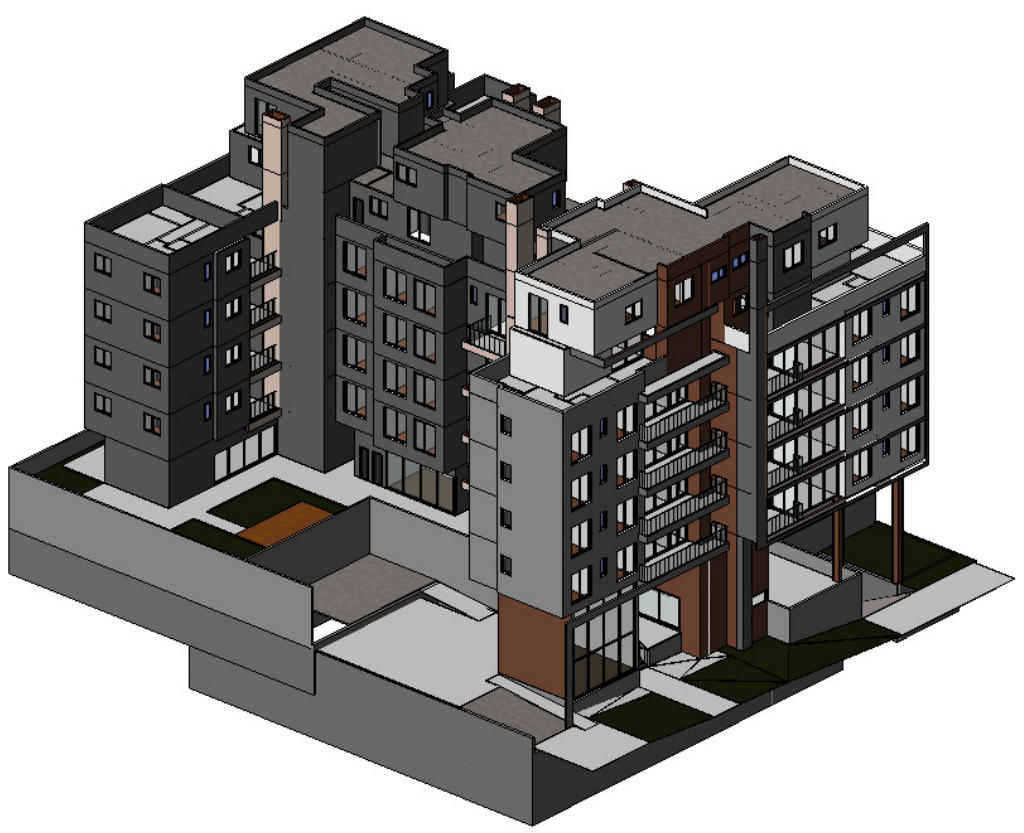

A empresa C utiliza um software chamado CGEP, programado em linguagem PHP (Personal Home Page) para efetuar a gestão do projeto e a orçamentação. Esta é uma linguagem de programação adequada para desenvolver conteúdo na World Wide Web (WEB). Até o momento, não há comercialização do software para outras empresas que utilizam processos BIM. A Figura 4 a seguir sintetiza o processo BIM da empresa C para a criação de um modelo com dados de custo para uso na orçamentação. 


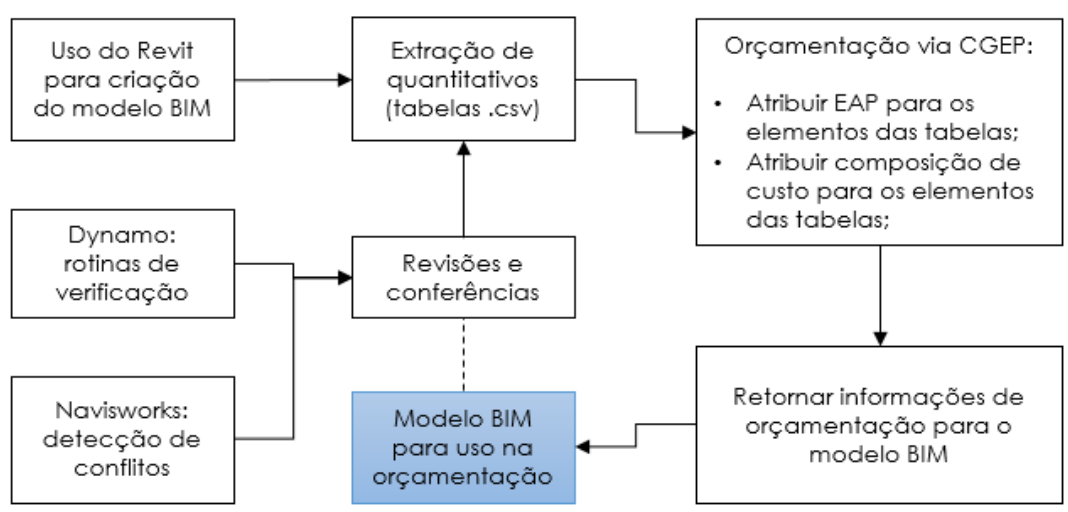

Figura 4: Processo BIM da empresa C

Fonte: Os autores.

\section{RESULTADOS}

$\mathrm{Na}$ Tabela 1, são apresentadas as quantidades obtidas para as atividades da planilha orçamentária. A coluna QUANT. A refere-se ao processo tradicional de orçamentação, enquanto a QUANT. B refere-se aos dados obtidos do processo BIM. É interessante notar que existem algumas atividades sem dados na coluna QUANT. B, o que significa que não foram informadas no software CGEP.

Tabela 1: Quantitativos A (processo tradicional) e B (processo BIM)

Fonte: Os autores

\begin{tabular}{l|l|l|l|l}
\hline ATIV. & DESCRIÇÃO DA ATIVIDADE & UN. & QUANT. A & QUANT. B \\
\hline 3.2 & Tela de fachada & $\mathrm{m}^{2}$ & 2.922 & \\
\hline 4.1 & Balancins e andaimes & $\mathrm{m}^{2}$ & 3.599 & \\
\hline 6.4 & $\begin{array}{l}\text { Limpeza permanente da obra - apartamentos e área } \\
\text { comum }\end{array}$ & $\mathrm{m}^{2}$ & $7.866,95$ & \\
\hline 8.5 & Aterro com rachão/saibro & $\mathrm{m}^{3}$ & 1.037 & \\
\hline 12.1 .1 & Alvenaria geral, platibandas, chaminés, dutos, guarda-corpo & $\mathrm{m}^{2}$ & $10.455,2$ & $10.399,15$ \\
\hline 12.1 .3 & Muros (subsolos e implantação) & $\mathrm{m}^{2}$ & $1.253,3$ & $1.092,34$ \\
\hline 12.1 .4 & Paredes em drywall ou placa cimentícia (shafts) & $\mathrm{m}^{2}$ & 238 & \\
\hline 12.2 .1 & Cobertura com telhas + estrutura de madeira & $\mathrm{m}^{2}$ & 355,7 & \\
\hline 13.1 & Cristalização & $\mathrm{m}^{2}$ & $1.505,3$ & \\
\hline 13.2 & Manta e proteção mecânica & $\mathrm{m}^{2}$ & $1.566,1$ & 2782,56 \\
\hline 14.1 & Contrapiso interno & $\mathrm{m}^{2}$ & $4.097,7$ & 4267,69 \\
\hline 14.2 & Contrapiso externo & $\mathrm{m}^{2}$ & $1.736,3$ & 1924,72 \\
\hline 14.4 & Emboço interno & $\mathrm{m}^{2}$ & $14.399,8$ & $14.797,10$ \\
\hline 14.5 & Embço externo fachada e implantação & $\mathrm{m}^{2}$ & $6.659,1$ & $5.778,84$ \\
& $\begin{array}{l}\text { (exceto muros). Inclui toda a parte de cobertura e área } \\
\text { técnica + muros terraço + dobras para telhados + chaminés } \\
\text { e dutos + floreiras }\end{array}$ & & & \\
\hline 14.6 & Emboço muros & $\mathrm{m}^{2}$ & $1.312,9$ & $1.200,84$ \\
\hline 15.1 & Pintura interna & $\mathrm{m}^{2}$ & $12.632,7$ & $13.630,12$ \\
\hline 15.2 & Pintura subsolos: tubulação, vagas, faixas & $\mathrm{m}^{2}$ & 2702,5 & \\
\hline 15.3 & Pintura subsolos: parede, pilares e teto & $\mathrm{m}^{2}$ & $3.461,5$ & 687,60 \\
\hline
\end{tabular}


Tabela 1: Continuação

\begin{tabular}{|c|c|c|c|c|}
\hline 15.4 & Textura rolada externa: muros térreos & $m^{2}$ & 601,4 & 984,62 \\
\hline 15.5 & Textura rolada interna: escadaria e área técnica & $\mathrm{m}^{2}$ & $1.619,7$ & 720,81 \\
\hline 15.6 & $\begin{array}{l}\text { Textura em argamassa projetada fachada e implantação } \\
\text { (exceto muros). Inclui toda a parte de cobertura e área } \\
\text { técnica + muros terraço + dobras para telhados + chaminés } \\
\text { e dutos + floreiras }\end{array}$ & $\mathrm{m}^{2}$ & $4.117,0$ & $5.196,60$ \\
\hline 15.7 & Pintura piso: escadaria e área técnica & $m^{2}$ & 411,0 & 275,44 \\
\hline 16.1 & Forro drywall & $\mathrm{m}^{2}$ & $4.106,3$ & $3.374,89$ \\
\hline 16.2 & Porcelanato piso & $\mathrm{m}^{2}$ & 2.516 & $1.626,76$ \\
\hline 16.3 & Cerâmica piso & $\mathrm{m}^{2}$ & 2.542 & $1.890,48$ \\
\hline 16.4 & Cerâmica parede & $\mathrm{m}^{2}$ & 4.326 & $3.453,27$ \\
\hline 16.5 & Litocerâmica e porcelanato fachada e implantação & $\mathrm{m}^{2}$ & 2.963 & 36,73 \\
\hline 16.6 & Piso laminado e piso vinílico & $m^{2}$ & 1.222 & $1.288,25$ \\
\hline 16.7 & Rodapé de cerâmica ou porcelanato & $\mathrm{m}$ & 991,8 & \\
\hline 16.8 & Rodapé de madeira & $\mathrm{m}$ & $2.920,9$ & \\
\hline 17.1 & Bancada de granito + acessórios & $\mathrm{m}^{2}$ & 79,8 & \\
\hline 17.3 & Granito piso/pórtico elevadores e escadas & $\mathrm{m}^{2}$ & 38,8 & \\
\hline 17.4 & Soleiras & $\mathrm{m}$ & 263,5 & 337,86 \\
\hline 18.1 & Portas de madeira & $\mathrm{m}^{2}$ & 483,0 & 478,77 \\
\hline 18.3 & Esquadrias de alumínio + vidros & $\mathrm{m}^{2}$ & $1.017,51$ & 916,65 \\
\hline 18.4 & $\begin{array}{l}\text { Guarda corpo com corrimão - externo (sacada, laje técnica } \\
\text { e térreo) }\end{array}$ & $\mathrm{m}^{2}$ & 216,8 & 172,14 \\
\hline 18.5 & Guarda corpo com corrimão - interno (duplex e mezanino) & $\mathrm{m}^{2}$ & 27,8 & \\
\hline 18.6 & Esquadria e vidro para janela especial guarita & $\mathrm{m}^{2}$ & 7,8 & 7,07 \\
\hline 18.7 & Brises metálicas em fachada & $\mathrm{m}^{2}$ & 35,9 & 48,46 \\
\hline 19.2 & Janela de aço escadaria & $\mathrm{m}^{2}$ & 10,4 & \\
\hline 19.4 & Corrimão metálico simples (escadas de incêndio) & $\mathrm{m}$ & 245 & \\
\hline 19.5 & Portão de veículos & $\mathrm{m}^{2}$ & 42,3 & \\
\hline 19.6 & $\begin{array}{l}\text { Gradil frontal com portão de pedestres e ventilação frontal } \\
\text { subsolo } 1\end{array}$ & $m^{2}$ & 81,6 & \\
\hline 23.1 & Paisagismo & $\mathrm{m}^{2}$ & 1.474 & \\
\hline 23.2 & Móveis e marcenaria & $m^{2}$ & 306 & \\
\hline 24.1 & Piso de concreto subsolo e rampas & $\mathrm{m}^{2}$ & $1.523,9$ & $1.581,19$ \\
\hline 24.2 & Calçadas e meio-fio & $\mathrm{m}^{2}$ & 182,0 & 81,88 \\
\hline
\end{tabular}

Existem 47 atividades listadas na tabela acima. No entanto, apenas 28 delas (60\%) possuem quantidades informadas no CGEP para o projeto em questão. Quando questionada sobre o motivo da falta dos dados, a empresa C informou que, por não haver informação suficiente no projeto arquitetônico fornecido, não houve modelagem de todas as atividades da lista.

Dentre as atividades que possuem dados informados nos dois processos orçamentários, é possível analisar a variação percentual entre os resultados. Além disso, é possível organizá-las de acordo com a curva $\mathrm{ABC}$ de atividades, cuja função é destacar as atividades que representam os maiores custos do orçamento. Para o estudo de caso foram inseridas no grupo A as atividades que, somadas em ordem decrescente de custo, representam $80 \%$ do custo total da obra (custo da atividade obtido via processo tradicional de orçamentação). No grupo C, estão contidas as atividades que somam 5\% do custo da obra quando somadas em ordem crescente de custos de cada atividade. No grupo B estão as atividades restantes que não se encontram dentro do grupo A e C, representando $15 \%$ do custo da obra.

Desta forma, a Tabela 2 descreve as atividades da Tabela 1, reorganizadas conforme curva $\mathrm{ABC}$ de atividades e conforme decrescente variação percentual entre os resultados dos quantitativos A e B. 


\begin{tabular}{|c|c|c|}
\hline CATEGORIA & DESCRIÇÃO DA ATIVIDADE & $\begin{array}{l}\text { VARIAÇÃO ENTRE } \\
\text { QUANTITATIVOS }\end{array}$ \\
\hline A & Litocerâmica e porcelanato fachada e implantação & $6104,5 \%$ \\
\hline A & Porcelanato piso & $43,7 \%$ \\
\hline A & Manta e proteção mecânica & $28,0 \%$ \\
\hline A & Cerâmica piso & $25,9 \%$ \\
\hline A & $\begin{array}{l}\text { Guarda corpo com corrimão - externo (sacada, laje técnica } \\
\text { e térreo) }\end{array}$ & $21,7 \%$ \\
\hline A & Forro drywall & $19,0 \%$ \\
\hline A & $\begin{array}{l}\text { Textura em argamassa projetada fachada e implantação } \\
\text { (exceto muros). Inclui toda a parte de cobertura e área } \\
\text { técnica + muros terraço + dobras para telhados + chaminés } \\
\text { e dutos + floreiras }\end{array}$ & $14,7 \%$ \\
\hline A & Emboço externo fachada e implantação & $11,0 \%$ \\
\hline A & Muros (subsolos e implantação) & $8,6 \%$ \\
\hline A & Esquadrias de alumínio + vidros & $7,3 \%$ \\
\hline A & Pintura interna & $4,8 \%$ \\
\hline A & Contrapiso interno & $4,0 \%$ \\
\hline A & Piso de concreto subsolo e rampas & $3,6 \%$ \\
\hline A & Emboço interno & $3,4 \%$ \\
\hline A & Portas de madeira & $2,7 \%$ \\
\hline A & $\begin{array}{l}\text { Alvenaria geral, platibandas, chaminés, dutos, guarda- } \\
\text { corpo }\end{array}$ & $0,9 \%$ \\
\hline $\mathrm{B}$ & Pintura subsolos: parede, pilares e teto & $403,4 \%$ \\
\hline $\mathrm{B}$ & Paisagismo & $261,3 \%$ \\
\hline $\mathrm{B}$ & Textura rolada interna: escadaria e área técnica & $124,7 \%$ \\
\hline B & Contrapiso externo & $9,8 \%$ \\
\hline $\mathrm{B}$ & Emboço muros & $9,3 \%$ \\
\hline B & Piso laminado e piso vinílico & $5,1 \%$ \\
\hline $\mathrm{C}$ & Calçadas e meio-fio & $122,3 \%$ \\
\hline $\mathrm{C}$ & Pintura piso: escadaria e área técnica & $49,2 \%$ \\
\hline C & Textura rolada externa: muros térreos & $38,9 \%$ \\
\hline C & Brises metálicos em fachada & $25,9 \%$ \\
\hline $\mathrm{C}$ & Cerâmica parede & $22,0 \%$ \\
\hline $\mathrm{C}$ & Soleiras & $10,3 \%$ \\
\hline $\mathrm{C}$ & Esquadria e vidro para janela especial guarita & $9,0 \%$ \\
\hline $\mathrm{C}$ & Corrimão metálico simples (escadas de incêndio) & $7,5 \%$ \\
\hline
\end{tabular}

Tabela 2: Variação entre quantitativos A e B organizada pela curva $A B C$

\section{Análise da comunicação}

Fonte: Os autores.

Levando em consideração a falta de dados para completar o conjunto de quantitativos $B$, é interessante investigar questões de comunicação e alinhamento entre os envolvidos. Visto que a EAP do projeto e a forma de quantificação das atividades foram informadas à equipe BIM em uma reunião que precedeu a modelagem, questionam-se quais motivos poderiam ter ocasionado esta ausência de dados. Vejamos o Quadro 1 a seguir. 


\begin{tabular}{|c|c|c|c|}
\hline $\begin{array}{l}\text { CÓDIGO } \\
\text { EAP }\end{array}$ & ATIVIDADE & $\begin{array}{l}\text { MOTIVOS PARA A AUSÊNCIA DE } \\
\text { QUANTITATIVO BIM }\end{array}$ & POSSÍVEL SOLUÇÃO \\
\hline 3.2 & Tela de fachada & $\begin{array}{l}\text { - Quantificação indireta pelo } \\
\text { perímetro da fachada; } \\
\text { - Não consta no projeto arquitetônico; } \\
\text { - Não é permanente. }\end{array}$ & $\begin{array}{l}\text { - Alinhamento sobre forma } \\
\text { de quantificação entre } \\
\text { orçamentista e empresa C. }\end{array}$ \\
\hline 4.1 & $\begin{array}{l}\text { Balancins e } \\
\text { andaimes }\end{array}$ & $\begin{array}{l}\text { - Quantificação indireta pela área de } \\
\text { emboço } \\
\text { - Não consta no projeto arquitetônico; } \\
\text { - Não é permanente. }\end{array}$ & $\begin{array}{l}\text { - Alinhamento sobre forma } \\
\text { de quantificação entre } \\
\text { orçamentista e empresa C. }\end{array}$ \\
\hline 6.4 & $\begin{array}{l}\text { Limpeza } \\
\text { permanente da } \\
\text { obra: apartamentos } \\
\text { e área comum }\end{array}$ & $\begin{array}{l}\text { - Não consta no projeto arquitetônico; } \\
\text { - Não é permanente. }\end{array}$ & $\begin{array}{l}\text { - Alinhamento sobre forma } \\
\text { de quantificação entre } \\
\text { orçamentista e empresa C. }\end{array}$ \\
\hline 8.5 & $\begin{array}{l}\text { Aterro com } \\
\text { rachão/saibro }\end{array}$ & $\begin{array}{l}\text { - Não consta no projeto arquitetônico; } \\
\text { - Quantificação indireta pela área de } \\
\text { piso de subsolo (subjetividade). }\end{array}$ & $\begin{array}{l}\text { - Alinhamento sobre forma } \\
\text { de quantificação entre } \\
\text { orçamentista e equipe } \\
\text { BIM. }\end{array}$ \\
\hline 12.1 .4 & $\begin{array}{l}\text { Paredes em drywall } \\
\text { ou placa cimentícia } \\
\text { (shafts) }\end{array}$ & $\begin{array}{l}\text { - Falha da orçamentista em não avisar } \\
\text { sobre a inclusão deste item na EAP. }\end{array}$ & $\begin{array}{l}\text { - Alinhamento sobre } \\
\text { revisões na EAP. }\end{array}$ \\
\hline 12.2 .1 & $\begin{array}{l}\text { Cobertura com } \\
\text { telhas + estrutura } \\
\text { de madeira }\end{array}$ & $\begin{array}{l}\text { - Motivo não identificado, visto que a } \\
\text { área de cobertura está no projeto } \\
\text { arquitetônico. }\end{array}$ & $\begin{array}{l}\text { - Revisar processo } \\
\text { orçamentário BIM. }\end{array}$ \\
\hline 13.1 & Cristalização & $\begin{array}{l}\text { - Empresa C não identificou locais } \\
\text { onde havia cristalização e } \\
\text { considerou apenas } \\
\text { impermeabilização com manta } \\
\text { asfáltica. }\end{array}$ & $\begin{array}{l}\text { - Revisar modelagem: } \\
\text { cristalização em sacadas e } \\
\text { áreas úmidas internas } \\
\text { (banheiro, e área de } \\
\text { serviço); } \\
\text { - Alinhamento sobre forma } \\
\text { de impermeabilização. }\end{array}$ \\
\hline 15.2 & $\begin{array}{l}\text { Pintura subsolos: } \\
\text { tubulação, vagas, } \\
\text { faixas }\end{array}$ & $\begin{array}{l}\text { - Subjetividade na forma de } \\
\text { quantificação: pintura de tubulação } \\
\text { estimada pela área de subsolo. } \\
\text { - Faixas de pilares e linhas de vagas } \\
\text { poderiam ser quantificadas. }\end{array}$ & $\begin{array}{l}\text { - Revisar processo } \\
\text { orçamentário BIM; } \\
\text { - Alinhamento entre } \\
\text { orçamentista e empresa C. }\end{array}$ \\
\hline 16.7 & $\begin{array}{l}\text { Rodapé de cerâmica } \\
\text { ou porcelanato }\end{array}$ & $\begin{array}{l}\text { - Motivo não identificado. Poderia } \\
\text { estar modelado. A informação de } \\
\text { rodapés consta no memorial } \\
\text { descritivo. }\end{array}$ & $\begin{array}{l}\text { - Revisar processo } \\
\text { orçamentário BIM. }\end{array}$ \\
\hline 16.8 & Rodapé de madeira & $\begin{array}{l}\text { - Motivo não identificado. Poderia } \\
\text { estar modelado. A informação de } \\
\text { rodapés consta no memorial } \\
\text { descritivo. }\end{array}$ & $\begin{array}{l}\text { - Revisar processo } \\
\text { orçamentário BIM. }\end{array}$ \\
\hline
\end{tabular}


Quadro 1: Continuação

\begin{tabular}{|c|c|c|c|}
\hline 17.1 & $\begin{array}{l}\text { Bancada de granito } \\
+ \text { acessórios }\end{array}$ & $\begin{array}{l}\text { - Motivo não identificado. Poderia } \\
\text { estar modelado. A informação } \\
\text { consta no projeto arquitetônico. }\end{array}$ & $\begin{array}{l}\text { Revisar processo } \\
\text { orçamentário BIM. }\end{array}$ \\
\hline 17.3 & $\begin{array}{l}\text { Granito piso/pórtico } \\
\text { elevadores e } \\
\text { escadas }\end{array}$ & $\begin{array}{l}\text { - Motivo não identificado. Poderia } \\
\text { estar modelado. A informação } \\
\text { consta no projeto arquitetônico. }\end{array}$ & $\begin{array}{l}\text { - Revisar processo } \\
\text { orçamentário BIM. }\end{array}$ \\
\hline 18.5 & $\begin{array}{l}\text { Guarda corpo com } \\
\text { corrimão - interno } \\
\text { (duplex e mezanino) }\end{array}$ & $\begin{array}{l}\text { - Motivo não identificado. Poderia } \\
\text { estar modelado. A informação } \\
\text { consta no projeto arquitetônico. }\end{array}$ & $\begin{array}{l}\text { - Revisar processo } \\
\text { orçamentário BIM. }\end{array}$ \\
\hline 19.2 & $\begin{array}{l}\text { Janela de aço } \\
\text { escadaria }\end{array}$ & $\begin{array}{l}\text { - Motivo não identificado. Poderia } \\
\text { estar modelado. A informação } \\
\text { consta no projeto arquitetônico. }\end{array}$ & $\begin{array}{l}\text { - Revisar processo } \\
\text { orçamentário BIM. }\end{array}$ \\
\hline 19.5 & Portão de veículos & $\begin{array}{l}\text { - Motivo não identificado. Poderia } \\
\text { estar modelado. A informação } \\
\text { consta no projeto arquitetônico. }\end{array}$ & $\begin{array}{l}\text { - Revisar processo } \\
\text { orçamentário BIM. }\end{array}$ \\
\hline 19.6 & $\begin{array}{l}\text { Gradil frontal com } \\
\text { portão de pedestres } \\
\text { e ventilação frontal } \\
\text { subsolo } 1\end{array}$ & $\begin{array}{l}\text { - Motivo não identificado. Poderia } \\
\text { estar modelado. A informação } \\
\text { consta no projeto arquitetônico. }\end{array}$ & $\begin{array}{l}\text { - Revisar processo } \\
\text { orçamentário BIM. }\end{array}$ \\
\hline 23.2 & $\begin{array}{l}\text { Móveis e } \\
\text { marcenaria }\end{array}$ & $\begin{array}{l}\text { - Quantificação subjetiva e indireta. É } \\
\text { baseada na soma de áreas comuns } \\
\text { do condomínio na planta do térreo }\end{array}$ & $\begin{array}{l}\text { - Alinhamento sobre forma } \\
\text { de quantificação entre } \\
\text { orçamentista e empresa C. }\end{array}$ \\
\hline
\end{tabular}

\section{Análise do tempo consumido para a revisão do orçamento}

Devido à necessidade de revisão do orçamento durante o estudo empírico, foi possível avaliar o tempo consumido para esse processo. Foi necessário revisar os orçamentos pois o projeto arquitetônico sofreu alterações na altura dos pés-direitos e na área comum do pavimento térreo. Tal alteração de orçamento durou cerca de uma semana no processo tradicional de orçamentação, enquanto o tempo para a revisão do modelo BIM e respectivos quantitativos foi de três dias. Dois dias para revisão da modelagem, e um dia para revisão da orçamentação via CGEP, segundo a empresa C.

\section{VERIFICAÇÃo}

A verificação dos quantitativos BIM fornecidos é necessária para confirmar se os objetos modelados e quantificados em cada atividade também são os mesmos que foram considerados no processo de quantificação tradicional.

Durante o processo do estudo empírico, a inspeção visual do modelo através do software Autodesk Navisworks foi uma maneira identificada para efetuar a verificação dos quantitativos BIM. Para a inspeção visual do modelo, é gerado um arquivo em formado NWD (Navisworks Document). A seguir, será apresentada a verificação da modelagem das atividades de alvenaria, muros, emboço dos muros, fachada e implantação. 
Figura 5: Inspeção da alvenaria no pavimento tipo

Fonte: Os autores

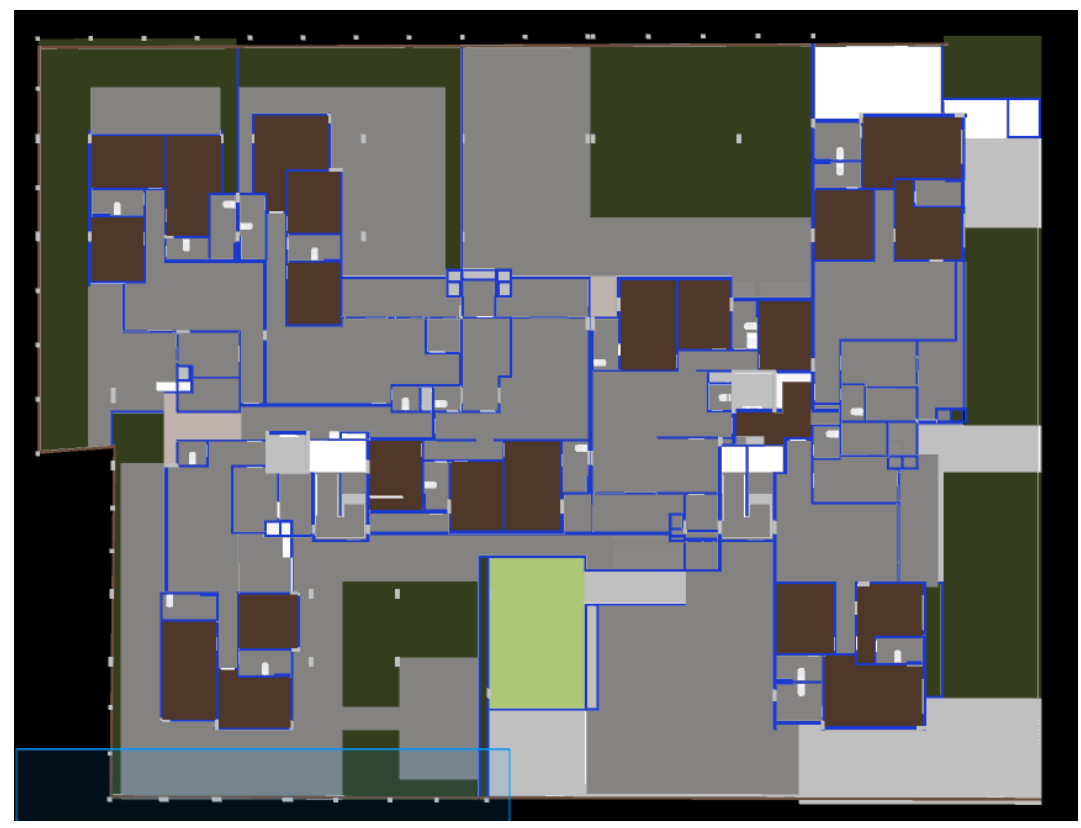

\section{Alvenaria e muros}

A alvenaria e muros são atividades quantificadas separadamente no processo tradicional, pois os custos de material e mão de obra são diferentes. Todavia, é mais prático executar a inspeção visual das duas atividades simultaneamente. Em cada plano de corte realizado no modelo pode ser visto com destaque o que foi modelado como muro e o que foi modelado como alvenaria, apenas alternando a seleção destas atividades no Navisworks.

A Figura 5 a seguir exibe um corte no pavimento tipo com uma vista do topo da edificação. Na imagem, a atividade "Alvenaria" está selecionada. A cor azul destaca os objetos modelados como alvenaria.

\section{Emboço muros, fachada e implantação}

Como acontece na inspeção visual da alvenaria e muros, também é conveniente realizar a inspeção visual da atividade de emboço da fachada, implantação e dos muros de forma simultânea. Nessa inspeção, foi observado que, para a fachada, a modelagem está aprovada. No entanto, alguns emboços de muros no pavimento térreo deveriam estar modelados na atividade "Emboço muros", mas estão modelados na atividade "Emboço externo fachada e implantação". A implantação é a região do pavimento térreo, onde há floreiras, guarita e paredes que ficam na área externa. Apesar de alguns muros do projeto estarem localizados na região implantação (além de existirem nos subsolos), esses muros deveriam estar considerados na modelagem da atividade "Emboço muros". Além disso, nos muros dos subsolos há locais em que não há emboço modelado. A correção destes detalhes possivelmente diminuiria as variações entre quantitativos, que são de 4,8\% e 9,3\% para as atividades "Emboço externo fachada e implantação" e "Emboço muros", respectivamente.

A Figura 6 é uma captura de tela obtida durante a inspeção visual. Nela é possível observar que alguns muros na região frontal do térreo e nas divisas entre áreas comuns estão destacados. Isso significa um erro de modelagem que deve ser corrigido, efetuando a troca para que estes sejam quantificados na atividade "Emboço muros”, e não em "Emboço da fachada e implantação". 


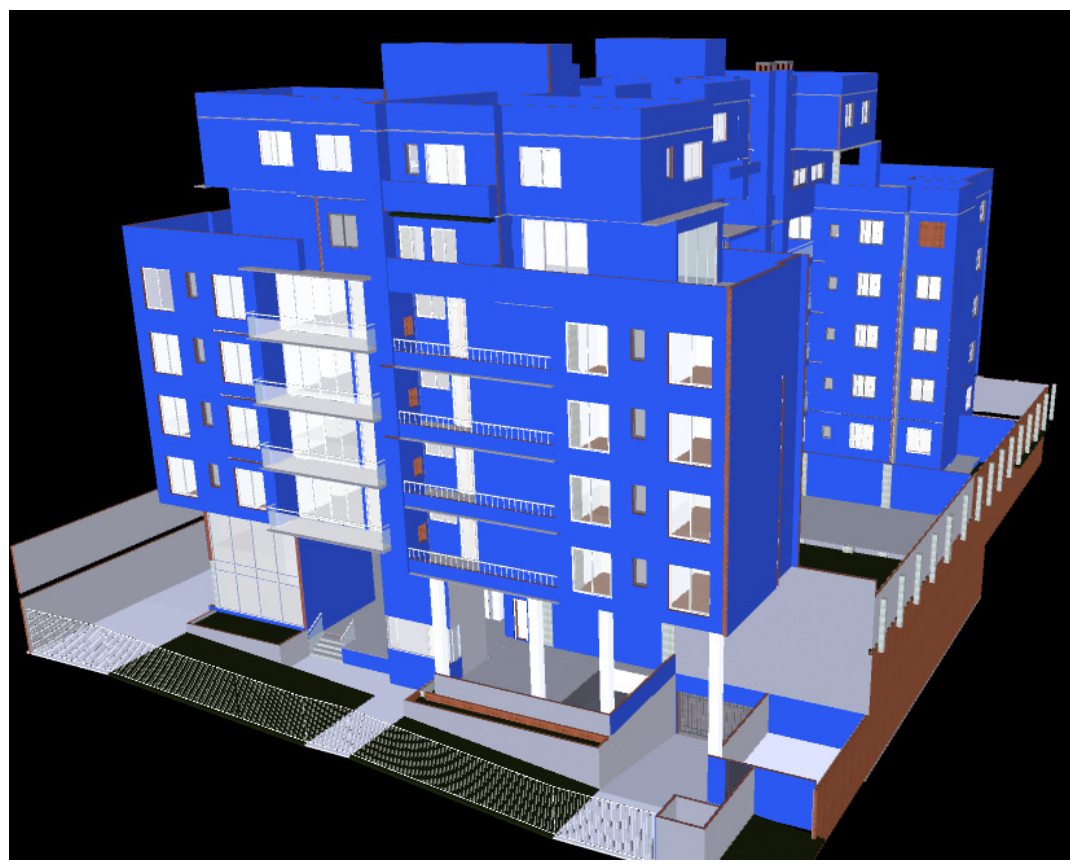

\section{CONSIDERAÇÕES FINAIS}

A falta de padronização na orçamentação é um pretexto para a lenta adoção de BIM nesse processo. A existência de normas visando à padronização podem colaborar com a adoção de BIM no processo orçamentário. A NBR 15965 (Sistema de classificação da informação da construção) define uma terminologia e sistema de classificação para todos os componentes, processos, espaços, unidades, materiais, equipamentos e suas respectivas propriedades que integram a construção. Essa norma já é uma referência para os processos de interoperabilidade e colaboração BIM (LEUSIN, 2018).

A contratação de serviços em tecnologia BIM agregou diversos benefícios ao processo de concepção do projeto e orçamentação para o empreendimento estudado. O primeiro benefício foi a rápida visualização 3D do projeto. Além disso, o BIM permite maior agilidade na tomada de decisão quando são estudadas alterações no projeto. As análises sempre existiram, mas com a utilização da modelagem BIM é notável a maior velocidade no processo. A alteração do orçamento se mostrou mais rápida no processo BIM do que no processo tradicional. Um dos motivos para a maior velocidade se dá pela possibilidade de comunicação direta entre o modelo e o orçamento.

Por outro lado, algumas quantidades necessárias para a análise dos resultados não foram geradas no processo BIM. Além disso, foi percebida uma grande variação entre os quantitativos obtidos no processo BIM e no tradicional. Essa grande variação reflete que a modelagem BIM não estava totalmente adequada para a extração de quantitativos. Os motivos apontados para essa variabilidade permeiam a necessidade de maior comunicação entre os envolvidos e estabelecimento de procedimentos de modelagem e quantificação, para que a subjetividade do processo orçamentário possa ser minimizada.

Os autores concluem que os quantitativos BIM podem ser utilizados em uma planilha orçamentária gerenciada por alguém que não está dentro da equipe BIM. Entretanto, durante a modelagem, é importante que se estabeleça uma frequência de comunicação entre o responsável pela planilha orçamentária e a equipe BIM. Desta forma, ao término da modelagem, menos ajustes serão necessários para a validação das atividades.
Figura 6: Inspeção visual do emboço da fachada e muros

Fonte: Os autores. 


\section{AGRADECIMENTO}

Ao Programa de Pós-Graduação em Engenharia de Construção Civil da Universidade Federal do Paraná e às empresas participantes do trabalho de pesquisa.

\section{REFERÊNCIAS}

ABANDA, F. H.; KAMSU-FOGUEM, B.; $\mathrm{TAH}$, J. H. M. BIM - New rules of measurement ontology for construction cost estimation. Engineering Science and Technology, an International Journal, v. 20, p. 443-459, 2017.

GIL, A. C. Métodos e técnicas de pesquisa social. São Paulo: Atlas, 2007.

HARRISON, C.; THURNELL, D. BIM implementation in a New Zealand consulting quantity surveying practice. International Journal of Construction Supply Chain Management, v. 5, n. 1, p. 1-15, 2015

HARTMANN, T.; MEERVELD, H.; VOSSEBELD B.; ADRIAANSE, A. Aligning building information model tools and construction management methods Automation in Construction, v. 22, $\mathrm{p}$. 605-613, 2012.

LATREILLE, D. Análise da validação de quantitativos obtidos de um modelo BIM de arquitetura para atender a estimativa orçamentária de empresas de construção civil. 2018. Dissertação (Mestrado em Engenharia de Construção Civil) - Universidade Federal do Paraná, Curitiba, 2018

LAWRENCE, M.; POTTINGER, R.; STAUBFRENCH, S.; NEPAL, M. P. Creating flexible mappings between Building Information Models and cost information Automation in Construction, v. 45, p. 107-118, 2014

LEE, S.; KIM, K.; YU, J. BIM and ontology-based approach for building cost estimation. Automation in Construction v. 41, p. 96-105, 2014

LEUSIN, S. BIM: Orçamentos e estimativas de custos. LigaBlog. 28 mai. 2018. Disponível em https://blogdaliga.com.br/ bim-orcamentos-e-estimativas-de-custos/. Acesso em: 28 jul. 2020.

LIU, H.; LU, M.; AL-HUSSEIN, M. Ontology-based semantic approach for construction-oriented quantity takeoff from BIM models in the light-frame building industry Advanced Engineering Informatics, v. 30, p. 190-207, 2016.
MONTEIRO, A.; MARTINS, J. P. A survey on modeling guidelines for quantity takeoff-oriented BIM-based design. Automation in Construction, v. 35, p. 238-253, 2013.

MONTEIRO, A.; MÊDA, P.; MARTINS, J P. Framework for the coordinated application of two different integrated project delivery platforms. Automation in Construction, v. 38, p. 87-99, 2014.

$\mathrm{SABOL}, \mathrm{L}$. Challenges in cost estimating with Building Information Modeling. IFMA World Workplace: 2008.

SAKAMORI, M. M. Modelagem 5D (BIM) - Processo de orçamentação com estudo sobre controle de custos e valor agregado para empreendimentos de construção civil. 177 p. Dissertação (Mestrado em Engenharia de Construção Civil) - Setor de Tecnologia da Universidade Federal do Paraná, Curitiba, 2015.

SUCCAR, B.; SALEEB, N.; SHER, W. Model Uses: Foundations for a Modular Requirements Clarification Language. Australasian Universities Building Education (AUBEA2016), 2016. 